\title{
MENINGOCOCCAL DISEASE: HISTORY, EPIDEMIOLOGY, PATHOGENESIS, CLINICAL MANIFESTATIONS, DIAGNOSIS, ANTIMICROBIAL SUSCEPTIBILITY AND PREVENTION
}

\author{
V Manchanda, S Gupta, *P Bhalla
}

\begin{abstract}
Meningoccocal disease has repeatedly caused outbreaks worldwide. There has been sudden surge of cases of meningococcemia and meningococcal meningitis in early 2005 in Delhi, India and neighboring states of Uttar Pradesh and Haryana. As of June 17, 2005, 429 probable cases of meningococcal disease have been reported in Delhi out of which 128 cases have revealed microbiological evidence of Neisseria meningitidis. It is possible that the number of cases was in excess of the numbers notified. During this episode drug susceptibility testing by MIC method (E-test) using break points recently recommended by NCCLS/CLSI, revealed that all isolates were sensitive to penicillin, ampicillin, rifampicin and ceftriaxone. As regards to ciprofloxacin, about two third of the isolates tested were found to be 'nonsusceptible' (MIC $=0.03 \mu \mathrm{g} / \mathrm{mL}-0.190 \mu \mathrm{g} / \mathrm{mL}$ ). All the isolates were found resistant to cotrimoxazole (MIC> $16 \mu \mathrm{g} / \mathrm{mL}$ ). Repeated outbreaks, decreased susceptibility to ciprofloxacin, which is commonly used for chemoprophylaxis of meningococcal disease, highlights the need for a constant surveillance system. Present review deals with various aspects of Neisseria meningitidis and meningococcal disease in view of recent episode.
\end{abstract}

Key words: Neisseria meningitidis, polysaccharide vaccines, ciprofloxacin resistance, outbreak, Delhi, India

\section{History}

Description of illness resembling meningococcal disease dates back to the 16th century. Meningococcal disease was described by Vieusseux in 1805 during an outbreak with 33 deaths in the vicinity of Geneva, Switzerland. ${ }^{1}$ The Italian pathologists Marchiafava and Celli first described intracellular oval micrococci in a sample of CSF. The Italian pathologists Marchiafava and Celli (1884) first described intracellular oval micrococci in a sample of CSF. ${ }^{2}$ However, Anton Weichselbaum in 1887 first identified bacterium causing meningococcal disease in the CSF of six of eight patients of bacterial meningitis and the bacterium was named Neisseria intracellularis. ${ }^{3}$

N. meningitidis causes a disease spectrum ranging from occult sepsis with rapid recovery to fulminant disease. Before the 1920s, meningococcal disease was fatal in up to 70 percent of cases. ${ }^{4}$ Serum therapy with serum from immunized horses, introduced at the beginning of this century by Jochmann in Germany and Flexner in the United States, could reduce mortality from nearly $100 \%$ to $30 \% .^{4,5}$ The discovery of

*Corresponding author (email: <manchandavikas@hotmail.com>) Department of Microbiology (VM, PB), Maulana Azad Medical College New Delhi-110 002, India; and Microbiology Division (SG), National Institute of Communicable Diseases, New Delhi-110 002, India.

Received : 27-06-05

Accepted : 14-07-05 sulfonamides and other antimicrobial agents led to a further decline in case fatality rates. Despite treatment with appropriate antimicrobial agents and optimal medical care, the overall case fatality rates have remained relatively stable over the past 20 years, at 9 to $12 \%$, with a rate of up to $40 \%$ among patients with meningococcal sepsis. ${ }^{6}$ Eleven percent to $19 \%$ of survivors of meningococcal disease have sequelae, such as hearing loss, neurological disability, or loss of a limb. ${ }^{7}$

\section{Microbiology}

On the basis of genome sequencing, Neisseria meningitidis is categorized as $\alpha$-proteobacteria related to Bordetella, Burkoholderia, Kingella and Methylomonas and more distantly related to Vibrio, Haemophilus and Escherichia coli. Meningococci are exclusively human, gram-negative, beanshaped aerobic diplococci that are best isolated on chocolate agar. Like most of the other members of its genus Neisseriae, these organisms are aerobic, non-motile, harbour oxidase enzyme, produce catalase, their growth is stimulated by $\mathrm{CO}_{2}$ and humidity and they produce acid from carbohydrates oxidatively. $N$. meningitidis, like other gram-negative bacteria, is surrounded by an outer membrane composed of lipids, outer membrane proteins (OMPs) and lipopolysaccharides. Pathogenic meningococci are enveloped by a polysaccharide capsule attached to this outer membrane. Meningococci reveal more genetic diversity than most other pathogenic human bacteria. This is explained partly by horizontal intraspecies recombination and incorporation from closely related Neisseria species. ${ }^{8}$ N. meningitidis is divided into 13 
serogroups (Table 1) defined by specific polysaccharides designated A, B, C, H, I, K, L, M, X, Y, Z, 29E and W135 (serogroup $\mathrm{D}$ is no longer recognized) and most infections are caused by organisms belonging to serogroups A, B, C, Y and $\mathrm{W}-135 .{ }^{9}$ Meningococci are further classified into 20 serotypes (on the basis of class 2 or 3 OMP antigens), 10 subtypes (identifying class 1 OMP antigens) and 13 immunotypes (on the basis of lipooligosaccharide antigens). ${ }^{9-11}$

Additional typing is possible by using the antigenic properties of immunoglobulin A1 (IgA1) proteases and pili. An example of this serological typing is B:4:P1.4:L3,7,9 indicating serogroup (B), serotype (4), subtype (P1.4) and immunotype. ${ }^{12}$ The capsular polysaccharide is a major virulence factor and is a homopolymer or a heteropolymer consisting of monosaccharide, disaccharide, or trisaccharide repeating units. Except for serogroup A, the capsules are composed of sialic acid ( $\mathrm{N}$ - acetyl neuraminic acid, NANA) derivatives. The serogroup B capsule is composed of $(\alpha 2 \rightarrow 8)$ linked NANA, the serogroup C capsule composed of $(\alpha 2 \rightarrow 9)$ linked NANA, the serogroup Y of alternating D-glucose and NANA and the serogroup W-135 capsule of D-galactose and NANA. The differences in sialic acid capsule composition are derived from the distinct polysialyl transferases encoded by the fourth gene of the capsule biosynthesis operon, which is the basis of capsule specific PCR. A four gene operon encoding capsule transport apparatus (ctr) is conserved among different serogroups and is used in PCR. ${ }^{13}$ The serogroup A capsule consists of repeating units of $\mathrm{N}$-acetyl-mannosamine1-phosphate and is encoded by a four gene biosynthesis cassette unique to this group.

Serotyping is of great importance for the development of vaccination strategies. Meningococci also have the capacity to exchange the genetic material responsible for capsule production and thereby switch from serogroup $\mathrm{B}$ to $\mathrm{C}$ or vice versa. ${ }^{14}$ Capsule switching may become an important mechanism of virulence with the widespread use of vaccines that provide serogroup-specific protection. However, although phenotypic characterization may reveal close genetic relatedness, serotyping is not suitable for modern epidemiologic purposes. ${ }^{8}$ Typing schemes based on variation of a few genes, which are probably under selection pressure, will not identify the overall relatedness of the chromosomal genome of $N$. meningitidis. ${ }^{8}$ Molecular subtyping with the use of multilocus enzyme electrophoresis, which identifies naturally occurring allelic variation in multiple chromosomal housekeeping genes, is being used worldwide. This technique classifies bacteria into Electrophoretic types (ETs). Strains belonging to the ET-37 clonal complex, which often express serogroup $\mathrm{C}$ capsule polysaccharide but also may express serogroup B, W-135 and Y, are found worldwide. ${ }^{8}$ In parts of the United States, serogroup Y strains belonging to the ET508 and related clones emerged in the mid-1990s as an important cause of endemic case clusters..$^{15}$ Other techniques to establish and identify relatedness among the strains include pulsed-field gel electrophoresis, or DNA-sequence analysis, can be helpful in identifying closely related strains with the potential to cause outbreaks and in understanding the genetic characteristics of $N$. meningitidis. ${ }^{16,17}$

\section{Epidemiology}

Meningococcal infections occur worldwide as endemic disease. ${ }^{8,18,19}$ Epidemiological studies by modern molecular methods has disclosed a complex picture of a few pathogenic meningococcal clones spreading worldwide. It appears that the occurrence of invasive meningococcal disease is not determined solely by the introduction of a new virulent bacterial strain but also by other factors that enhance transmission. ${ }^{15}$

Of the five common serogroups (A, B, C, Y and W135) responsible for about $90 \%$ of infections caused by $N$. meningitidis, serogroups $\mathrm{A}, \mathrm{B}$ and $\mathrm{C}$ account for most cases of meningococcal disease throughout the world, with serogroups $\mathrm{A}$ and $\mathrm{C}$ predominating throughout Asia and Africa and serogroups $\mathrm{B}$ and $\mathrm{C}$ responsible for the majority of cases in Europe and the Americas. ${ }^{8,18-21}$ In recent years, the number of cases involving serogroup Y has increased; from 1996 to 1998 , one third of cases in United States were due to serogroup Y. ${ }^{22}$ Israel and Sweden are the only countries other

\section{Table 1: Classification based on outer-membrane components of $N$. meningitides}

\begin{tabular}{llccl}
\hline Bases & Function & $\begin{array}{c}\text { Classification } \\
\text { System }\end{array}$ & $\begin{array}{c}\text { Number of } \\
\text { groups }\end{array}$ & Names \\
\hline Capsule & $\begin{array}{l}\text { Protects against complement dependent } \\
\text { bacteriolysis and phagocytosis }\end{array}$ & Serogroups & 13 & A, B, C, E-29, H, I, K, \\
& & & L, M, W-135, X,Y, Z \\
$\begin{array}{l}\text { Outer membrane proteins } \\
\text { (porins) }\end{array}$ & $\begin{array}{l}\text { Creates pores theough which small } \\
\text { hydrophilic solute pass, cation - selective } \\
\text { or anion selective }\end{array}$ & & & \\
PorA (Class 1 OMP) & & Subserotypes & 10 & P1.1, P1.2, P1.3... \\
$\begin{array}{l}\text { PorB (Class 2/3 OMP) } \\
\text { Lipooligosaccharide (LOS) } \\
\text { Pili }\end{array}$ & $\begin{array}{l}\text { Has potent immunotoxic activity } \\
\text { Promote initial adherence to epithelial/ }\end{array}$ & Serotypes & 20 & $1,2 \mathrm{a}, 2 \mathrm{~b}, \ldots .21$ \\
& Immunotypes & 13 & L1, L2, ... L13 \\
& endothelial cells and red blood cells & & 2 & I, II
\end{tabular}


than the United States that have reported an increase in serogroup Y disease (ET-508). ${ }^{21}$ Serogroup W-135, currently accounting for only $4 \%$ of cases in the United States, was reported in 15 to $20 \%$ of isolates received by the Centers for Disease Control and Prevention between 1978 and 1980. ${ }^{23}$ In 2000, an international outbreak among pilgrims returning from the hajj (the pilgrimage to Mecca) and their close contacts, including four persons from the United States, was due to serogroup W135. ${ }^{24}$ Recently, serogroup W135 has been associated with an outbreak amongst Hajj pilgrims as well as a large epidemic in Burkina Faso during 2002 and 2003..$^{25-27}$

Epidemic rates of meningococcal disease varies from $<1$ $3 / 100,000$ in many developed nations to $10-25 / 100,000$ in some developing countries. This difference in attack rates reflects the difference in pathogenic properties of $N$. meningitidis strains prevalent and differences in socioeconomic and environmental conditions. The proportion of cases caused by each serogroup varies by age group; more than half of cases among infants aged $<1$ year are caused by serogroup $\mathrm{B}$, for which no vaccine is available. ${ }^{22,28}$

Epidemics due to strains of $N$. meningitidis belonging to atleast seven clonal groups have been identified. Strains belonging to the ET-37 clonal complex, whose origin can be traced back to 1917, which often express serogroup C capsule polysaccharide but also may express serogroup B, W-135 and $\mathrm{Y}$, are found worldwide. ${ }^{8}$ The strain has been reported in United States, Brazil and China. Another ET-37 variant stain designated ET-15 emerged in late 1980s in United States and in the 1990s, these strains caused outbreaks in Israel, the Czech Republic, Australia, England and Canada. ${ }^{8,29}$ There have been epidemics in Europe and in the Americas during the last 30 years, but they have not reached the very high incidence levels of epidemics as in other parts of the world. In the late 1970s, a serogroup B strain belonging to a clonal group known as ET-5 emerged, causing outbreaks in northwestern Europe and Central and South America. ${ }^{28}$ First discovered in the Netherlands in 1980, strains belonging to another serogroup B clonal complex designated lineage III (ET-24 and ET-25) emerged in Europe. ${ }^{30}$ Serogroup B meningococcal disease caused 68\% of cases reported in Europe between 1993 and 1996 and has also caused outbreaks in developed countries, with attack rates of 5 to 50 cases per 100,000 persons. ${ }^{21,28}$

The largest and most frequently recurring outbreaks have been in the semi-arid area of sub-Saharan Africa. In the African "meningitis belt," a region of savannah that extends from Ethiopia in the east to Senegal in the west, serogroup A meningococcal disease has posed a recurrent threat to public health for at least 100 years. ${ }^{31}$ In 1996, the largest outbreak ever reported occurred in the meningitis belt; the total number of cases reported to the World Health Organization (probably a substantial underestimate) was 152,813 , with 15,783 deaths. ${ }^{32}$ The response to the epidemic by these countries exhausted international stocks of vaccine. Following large outbreaks in Africa in 1995-96, in 1997, the International
Coordinating Group (ICG) for Vaccine Provision for Epidemic Meningitis Control was established. Main aims of ICG are to ensure rapid and equal access to vaccines, injection material and oily chloramphenicol and to ensure their adequate use when the stocks are limited. The ICG is composed of partners from the UN, including WHO, nongovernmental organizations, technical partners and the private sector.

Asia has been focus of some major epidemics of meningococcal disease in the last 30 years (China 1979 and 1980, Vietnam 1977, Mongolia 1973-1974 and 1994-1995, Saudi Arabia 1987, Yemen 1988). ${ }^{33}$ The largest outbreaks, which originated in northern China and spread to the south and later globally, were caused by two clones of serogroup A. $8,19,33$ One of these clones spread to the Indian subcontinent in 1983 to 1987. Between 1987 to 1996, this clone traveled through the Middle East causing epidemic among pilgrims during the Haj in Mecca to African countries. ${ }^{8,19,33}$ In 1985, Bhutan was also hit by meningitis and 247 cases with 41 deaths were reported between September 1985 and March 1986. ${ }^{34}$ During 1982-1984, 1475 cases occurred in Kathmandu valley, Nepal, with highest mortality and morbidity in children less than one year of age. Serogroup B strains are common in developing countries. Most of these strains belong to a few clonal complexes, identified as ET-5, lineage III, cluster A4 and ET-37. ${ }^{8}$

\section{Indian scenario}

Meningococcal disease is endemic in Delhi and sporadic cases of meningococcal meningitis have been occurring in Delhi in the past. ${ }^{35}$ Isolated cases of meningococcal meningitis during 1985 were also reported from several states of India including Haryana, Uttar Pradesh, Rajasthan, Sikkim, Gujarat, Jammu \& Kashmir, West Bengal, Chandigarh, Kerala and Orissa. ${ }^{36}$ Serogroup A has been associated with all the repeated outbreaks of meningitis, although serogroup B and C have been detected in a few sporadic cases. ${ }^{37-40}$

An outbreak of pyogenic meningitis occurred in western part of India (Surat, Gujrat) during 1985-87.41 A total of 197 cases of meningitis with 34 deaths were reported during a period of one-and-a-half years. N. meningitidis was the predominant pathogen isolated from 66 out of 138 CSF samples. Recently migrated males of productive age groups drawn from the States of Uttar Pradesh and Orissa were predominantly affected. Male to female ratio was found to be 7.2:1. Pregnancy and childbirth appeared to be important predisposing factors in females. Nine cases were reported from the family contacts of cases.

Many outbreaks of meningococcal meningitis have been documented during 1966 and 1985 in Delhi and its adjoining areas. ${ }^{35}$ During 1966, 616 cases of meningitis were reported with case-fatality rate of $20.9 \%$. The highest proportion of cases and deaths occurred in age group less than one year followed by that in 1-4 years. However, grouping of $N$. 
meningitidis could not be performed. ${ }^{34,35}$ A larger outbreak occurred in 1985 with greater number of cases than previous years and larger geographical area being affected. ${ }^{42}$

In early 2005, spurt of cases of meningoccemia and meningitis due to $N$. meningitidis serogroup A have been reported from Delhi and adjoining areas. As of June 17, 2005, 429 probable cases of meningococcal disease have been reported. Among these, 128 cases have revealed microbiological evidence (i.e, positive for direct microscopy/ direct latex antigen detection/culture) of meningococci. Of these, 40 cases were culture positive for meningococci. The majority of cases and all deaths occurred in young adults between $16-30$ years of age..$^{34}$ It is possible that the number of cases was in excess of the numbers notified. Clinically suspected cases of meningococcemia and meningococcal meningitis were being diagnosed and managed in almost all the major hospitals of Delhi and N. meningitidis serogroup A was isolated from a variable number of cases. Most of the reported cases were from the walled city of Old Delhi and Shahdara with a few cases being reported from the neighboring states of Uttar Pradesh and Haryana. The National Institute of Communicable Diseases (NICD) had been identified by Ministry of Health and Family Welfare as the nodal agency for investigation of this episode and provided laboratory support. The spurt of cases has waned off in late June 2005 but not completely disappeared.

\section{Transmission and risk factors}

\section{Transmission}

The human naso-oropharyngeal mucosa is the only natural reservoir of $N$. meningitidis. Meningococci are transferred from one person to another by direct contact or via droplets. During periods of endemic infection, 8 to $20 \%$ of adults are asymptomatic nasopharyngeal carriers of strains of $N$. meningitidis, most of which are not pathogenic. ${ }^{33,43}$ The carriage may be transient, intermittent, or persistant. Carriage strains may be encapsulated (groupable) or nonencapsulated (ungroupable). ${ }^{43}$ The carriage rate of meningococci is higher in lower socioeconomic classes, in military recruits, pilgrims, boarding-school students and prisoners. ${ }^{44,45}$ In households where a case of meningococcal disease has occurred, the risk of invasive disease in family members is increased by a factor of 400 to $800 .{ }^{46}$ The transmission rate of virulent clones is higher and invasive disease often occurs within the first week after acquisition, whereas some persons may carry pathogenic meningococci for many months or years without becoming ill. ${ }^{33}$ Various bacterial factors (virulence factors) as well as host factors influence the outcome of exposure to strains of N. meningitidis.

\section{Host factors}

Only in few persons, $N$. meningitidis penetrates the mucosa and gains access to the bloodstream, causing systemic disease. ${ }^{47}$ In normal individuals, humoral immunity is important and has been demonstrated to have an inverse correlation between the age-related incidence of disease and the age-related acquisition of serum bactericidal antibodies. ${ }^{48}$ The incidence of meningococcal disease is highest at 6 to 24 months of age, when maternal antibodies have disappeared ${ }^{44,45}$ In most persons, nasopharyngeal carriage is an immunizing process, resulting in a systemic protective antibody response. ${ }^{15}$ Most adults and children harbor the nonpathogenic Neisseria lactamica.$^{49}$ Throughout life, specific antibodies are induced by the continuously repeated and intermittent carriage of different meningococci and $N$. lactamica. ${ }^{44,45,49}$ Individuals who are colonized with nongroupable strains (non-encapsulated strains) develop high titers of antibody against groupable strains, probably due to shared antigenic determinants. This response does not eliminate the carriage state, but it may protect them from overt disease. Structurally and immunologically identical capsule have been observed in case of Bacillus pumilus with serogroup A meningococci and for Escherichia coli $\mathrm{K} 1$ with serogroup B strains. ${ }^{50,51}$ It has been suggested that these bacteria contribute to the defense against meningococci by the induction of cross-reacting antibodies. ${ }^{51}$ The timing of exposure to meningococcus and cross reacting enteric bacterium may be critical. ${ }^{43}$

Underlying immune defects that confer a predisposition to invasive meningococcal infection include asplenia, a deficiency of properdin and a deficiency of antibodydependent, complement-mediated immune lysis (bactericidal activity) i.e, deficiencies in the terminal common complement pathway (C3, C5-9). ${ }^{52}$ Persons who have certain social conditions like household crowding and both active and passive smoking are associated with increased risk for meningococcal disease. ${ }^{53}$ Persons with antecedent upper respiratory tract infections with Mycoplasma pneumoniae or virus (influenza A virus) or having chronic underlying illness like hepatic failure, systemic lupus erythematosis and multiple myeloma are also at increased risk and increased severity of meningococcal illness. The exact cause of this preceding infection promoting invasion is not known but it may be due to increased mechanical transmission of meningococci by sneezing and coughing or it may be due to post-viral immune suppression..$^{53}$

Those infected with the human immunodeficiency virus are probably also at increased risk for sporadic meningococcal disease, but the risk is not nearly as high as that of infection with other encapsulated organisms, such as Streptococcus pneumoniae. ${ }^{46}$ The role of genetic immune defects, such as polymorphisms in the genes for mannose-binding lectin and tumor necrosis factor-alpha, may have major roles in altering the susceptibility to meningococcal disease, however additional research is needed in this regard. ${ }^{46}$ 


\section{Bacterial factors}

Meningococci are diverse organisms and are usually commensal bacteria present in nasopharynx in humans. Only a minority of the nasopharyngeal isolates cause invasive disease. Meningococci associated with invasive disease elaborate a capsule, which provides protection from desiccation during transmission and aids in the evasion of host immune mechanisms. In addition, adhesins, such as pili and specific nutrient-acquisition factors, especially mechanisms for acquiring iron from human lactoferrin, transferrin and hemoglobin, enhance their pathogenic potential. ${ }^{46}$ A major factor in the virulence of the organism is the release of outermembrane vesicles that consist of lipooligosaccharide (endotoxin), outer-membrane proteins, phospholipids and capsular polysaccharides. Lipid A molecules of lipooligosaccharide (LOS) act as endotoxins and their effects are due to interaction with innate immune receptors. The endotoxin of $N$. meningitidis is structurally distinct from the lipooligosaccharide of enteric gram negative bacteria. Finally, the expression of pili, class 5 OMPs, capsule and LOS is highly variable and subject to phase switching (on/off) and antigenic variation. ${ }^{33}$ These mechanisms can be used by the bacterium to circumvent host immunity.

\section{Pathophysiology and natural history}

At least three conditions are required to cause an invasive disease. ${ }^{18}$ These conditions are (i) exposure to a pathogenic strain, (ii) acquisition of pathogenic strain (i.e, its colonization on the naso-oropharyngeal mucosa) and (iii) invasion of bacteria. Invasion can be subdivided into mucosal penetration followed by invasion of blood stream and finally, invasion of meninges. These processes are influenced by bacterial properties, environmental and social conditions, preceding or concomitant viral infections and the immune status of the patient.

Exposure depends on frequency and intimacy of interaction between colonized and susceptible individuals to disseminate bacteria from nasopharynx. Meningococci overcome host defenses and bind to the microvillous surface of nonciliated columnar mucosal cells of the nasopharynx, where they multiply (i.e, colonize).$^{54}$ Pili are the major adhesins that may target the CD46 receptor, a membrane cofactor protein; subsequently, the opacity-associated proteins, Opa and Opc, bind to CD66 and heparan sulfate proteoglycan receptors, respectively. ${ }^{46}$ Various factors of transmission and acquisition have been dealt earlier in this article.

Different bacterial strains vary in their capacity to invade. Non-capsulate meningococci are avirulent and serogroups A, $\mathrm{B}, \mathrm{C}$ are more invasive than other serogroups of meningococci. Toll-like receptor 4 (TLR4) is associated with the membrane protein 2 (MD2). TLR4 and MD2 are mainly found on macrophages/monocytes, dendritic cells and other phagocytes. Binding stimulates engulfment of the meningococci by epithelial cells, which may then traverse the mucosal epithelium through phagocytic vacuoles. ${ }^{54}$ The survival of meningococci in the epithelial cells may be promoted by the IgA1 protease and by porB. ${ }^{46}$

Skin haemorrhages are the hallmark of invasive meningococcal disease. Microscopically, these lesions are characterized by endothelial damage and haemorrhages and microthrombi in small vessels, consistent with a generalized Sanarelli-Shwartzman reaction. The lesions are a reflection of the endotoxin- and cytokine-primed vasculitis that is mediated by the upregulation of adhesion molecules on endothelium and degranulating activated neutrophils. ${ }^{33}$ Although DIC is a generalized phenomenon affecting all organs, the adrenals are particularly vulnerable. Adrenal haemorrhages, diagnosed postmortem as Waterhouse-Friderichsen syndrome, may lead to transitory adrenal insufficiency. ${ }^{33}$

The cerebral capillary endothelium binds bacteria. Bound bacterium may undergo fimbrial phase variation in order to cross blood brain barrier. ${ }^{43}$ Bacteria may also gain access to subarachnoid space within host phagocytic cells. ${ }^{43}$ Once in the subarachnoid space, where the principal humoral and cellular host defense mechanisms are absent, there is uncontrolled proliferation of meningococci. The evolving endotoxin liberation elicits compartmentalized (i.e, confined to the subarachnoid space) activation of proinflammatory cytokines. The subsequent release of neutrophil products contributes to the development of clinically overt meningitis.

\section{Clinical manifestations}

Based on the sequence of pathophysiological events, agent and host factors wide spectrum of presentations may be observed. Patients with invasive meningococcal disease can present with: (i) bacteraemia without shock (acute mild meningococcemia), (ii) bacteraemia with shock but no meningitis (fulminant meningococcaemia), (iii) shock and meningitis, (iv) meningitis alone and (v) chronic benign meningococcemia (http://www.vh.org/adult/provider/ internalmedicine/AdultCriticalCare/FM/Overview.html). Factors influencing type of disease a patient will develop, depends on the duration of disease before hospitalization; the site, severity and pattern of mediator activation; and the prognosis. Classification of patients into one of these clinically easily recognizable groups is a great help for clinical decision making, particularly for the installation of immediate and maximal intensive care support.

Meningeal infection, resulting from haematogenous spread, occurs in about 50 to $55 \%$ percent of patients and is similar to other forms of acute purulent meningitis. $N$. meningitidis can be isolated from the bloodstream in up to $75 \%$ of patients, but meningococcaemia, occurs in only 5 to $20 \%$ of patients. ${ }^{22}$ The early symptoms are determined by the sudden entry of meningococci in the bloodstream thus may resemble fulminant meningococcaemia (FMS). The 
characteristic haemorrhagic skin lesions develop only in $80 \%$ of the patients and become apparent only 12 to 18 hours after first disease symptoms. The CSF may contain normal chemistry and cell counts. Neurological sequelae varying from sensorineural deafness, mental retardation, spasticity and/or seizures to concentration disturbances have been observed in 8 to $20 \%$ of survivors. ${ }^{44}$

Less than $1 \%$ of patients, mainly adults, can present with one or more episodes of spiking fever, arthralgia, or arthritis and a recurrent rash; this syndrome is designated chronic benign meningococcemia. ${ }^{33}$ How these patients tolerate the potentially lethal bacteria for several weeks in their bloodstream is not understood. These patients develop recurrent fevers over days to several weeks. About $20 \%$ will later develop meningitis. Blood cultures during febrile episodes are not consistently positive and they are usually negative when patients are afebrile. The source of the organism during the recurrent febrile episodes is unknown.

\section{Other infections due to $N$. meningitides}

Compartmentalized metastatic infections, such as arthritis or pericarditis, can develop; the latter is caused mainly by serogroup C. ${ }^{57,58}$ The pericarditis that occurs in the first few days of meningococcal disease may demonstrate the organism. Late onset pericarditis, one to two weeks after infection, may contain no organisms. Arthritis occurs commonly during active meningococcal infection. There may be late onset arthritis, after resolution of meningococcal infection. Less commonly, septic purulent arthritis may occur spontaneously in the absence of meningococcal disease elsewhere. Cellulitis and endophthalmitis have been found occasionally. ${ }^{59}$ Additionally, primary meningococcal conjunctivitis, pneumonia, sialadenitis, adnexitis, or pelvic inflammatory disease have been reported. Meningococcal infections in the upper or lower airways, genitals and anus differ from invasive disease as they develop without preceding bacteraemia. ${ }^{59}$ Meningococcal pneumonia is uncommon and generally occurs in immunocompromised or elderly patients. ${ }^{60}$

\section{Diagnosis}

Bacteriological diagnosis in patients with meningococcal disease is possible with a Gram stain, direct antigen detection using latex agglutination, or culture. Molecular diagnosis using polymerase chain reaction(PCR) has also been used. ${ }^{61}$ In patients with meningococcemia blood, skin lesion biopsy specimen, or CSF may be collected. In patients with meningococcal meningitis, skin lesions seldom reveal meningococci, blood cultures may not be always revealing and only CSF samples are generally positive. ${ }^{62}$ Body fluids like joint fluid, pericardial fluid may be bacteriologically positive only in early onset compartmentalized infections.

Since N. meningitidis are fastidious and fragile bacteria, isolation rates can be increased if the clinical material is examined as soon as possible after collection. Ideally, as soon as the CSF has been collected, it should be transported to the microbiology laboratory, where it should be examined within one hour from the time of collection. In case, delay of several hours is anticipated, the sample may be incubated (with screwcaps loosened) at $35^{\circ} \mathrm{C}$ in a $5 \% \mathrm{CO}_{2}$ atmosphere (or candlejar) or may be inoculated aseptically into a recently developed biphasic medium (Trans-Isolate medium) to enhance the recovery of causative organism. ${ }^{63,64}$

Gram staining of cerebrospinal fluid is still considered an important method for rapid detection of $N$. meningitidis. ${ }^{65}$ However, definitive diagnosis of meningococcal disease has relied on bacteriologic culture. Recovery of meningococci from blood cultures may be adversely affected by the anticoagulant sodium polyanethol sulphonate that is present in the blood culture media. This effect may be neutralized by addition of sterile gelatin (1\% final concentration) to the media or by processing the samples by lysis centrifugation technique. However, the sensitivity of culture may be low, especially when performed after the initiation of antibiotic treatment. Prior antibiotic therapy jeopardizes the recovery of bacteria from cultures of blood and CSF but not from skin biopsy specimens. ${ }^{62}$ Other methods not affected by prior antibiotic administration are antigen detection or PCR in blood or CSF. ${ }^{61}$

Direct examination of the CSF or skin lesion biopsy specimen using gram staining reveals gram-negative diplococci both inside and outside of polymorphonuclear cells. Organisms may show considerable size variation and tend to resist decolorisation. Heavily capsulated strains may have distinct pink halo around the cells. Quantitation of pus cells and organisms should be reported as this has value in prognostic scoring.

Direct tests of detection of meningococcal capsular polysaccharide in CSF, serum or urine can also be done using commercially available kits based on antibody coated latex agglutination to detect capsular antigen of meningococcal serogroups $\mathrm{A}, \mathrm{B}, \mathrm{C}, \mathrm{Y}$ and $\mathrm{W}-135$. If immediate testing is not possible, the sample can be refrigerated (between $2^{\circ} \mathrm{C}$ and $8^{\circ} \mathrm{C}$ ) up to several hours, or frozen at $-20^{\circ} \mathrm{C}$ for longer periods. This method is rapid, specific and can provide a serogroup-specific diagnosis, but false negative results are common, especially in cases of serogroup B disease. ${ }^{66}$ Antigen tests of urine or serum are less reliable for the diagnosis of meningococcal disease. Negative direct Gram stain or antigen detection does not rule out meningococcal disease.

Non-selective chocolate agar and sheep blood agar should be used for recovery of $N$. meningitidis from CSF, blood and aspirates. Plates should be incubated in $5-7 \% \mathrm{CO}_{2}$ at $35^{\circ} \mathrm{C}$ and should be reported "no growth" only after 72 hours of examination. ${ }^{66}$ Suspected colonies of $N$. meningitidis are gray colored, about $1 \mathrm{~mm}$ diameter, low convex, with smooth moist entire edge and glistening surface. The medium beneath and adjacent to the colonies may exhibit a gray green cast, particularly in areas of confluent growth. From growth on a 
blood agar plate, Kovac's oxidase test should be performed and then the serogroup should be identified. ${ }^{63}$ Finally, carbohydrate utilization tests should be used for confirmation of isolates as $N$. meningitidis.

Routine susceptibility testing of all meningococcal isolates is not necessary; however, such testing should be performed if a patient does not show an appropriate response to antimicrobial agents. Antimicrobial susceptibility testing using MIC determination is the method of choice. ${ }^{67}$ According to recent recommendations from NCCLS/CLSI either broth microdilution or agar dilution MIC testing of $N$. meningitidis by using cation-supplemented Mueller Hinton broth with 25\% laked horse blood or Muller Hinton agar with 5\% (v/v) sheep blood respectively can be used. ${ }^{67}$ The E-test can also be used ${ }^{68}$ Molecular diagnosis using PCR analysis offers the advantages of detecting serogroup-specific $N$. meningitidis DNA and of not requiring live organisms for a positive result. Hence, the technique is useful in cases where antibiotic therapy has been started. Moreover, a study comparing the results of Gram staining and culture of cerebrospinal fluid to results obtained with a rapid PCR assay for the diagnosis of meningococcal meningitis in 281 cases of suspected bacterial meningitis has shown that PCR had a sensitivity of $97 \%$ compared to a sensitivity of $55 \%$ for culture and the PCR specificity was $99.6 \%$. PCR results were available within two hours of the start of the assay ${ }^{69} \mathrm{PCR}$ based on various primers encoding $\operatorname{ctr} A$, por $A, \operatorname{crg} A, 16 \mathrm{~S}$ rRNA, siaD and nsp $A$ have been developed. ${ }^{13,70-72}$ Real-time PCR based on the capsule transfer gene (ctrA) is a significant aid in the diagnosis of meningococcal infection but fails to detect a high proportion $(60 \%)$ of non-groupable strains associated with nasopharyngeal carriage..$^{70}$ A novel porA-based TaqMan assay has been developed which reportedly has been found as a highly specific method for detecting meningococcal DNA that is more sensitive than the ctrA assay for detecting meningococcal carriage and is particularly suitable for carriage studies where non-groupable strains and other Neisseria are present. ${ }^{70}$ Serogroup specific real time PCR has also been used efficiently to resolve slide agglutination serogrouping discrepancies as over reporting of the isolates as nongroupable. ${ }^{73}$ Recently a multiplex PCR assay for the detection of $N$. meningitidis, Streptococcus pneumoniae and Haemophilus influenzae type $\mathrm{b}$ have been developed based on the ctrA, ply and bex targets, respectively, enabled detection of 5-10 pg DNA. The sensitivity for the three targets was found to be $93.9 \%, 92.3 \%$ and $88 \%$, respectively, while the overall specificity and positive predictive value of the assay was found $100 \%$. The negative predictive value was 99.1$99.5 \% .{ }^{74}$

Serotyping and subserotyping of $N$. meningitidis isolates can be done during epidemiological studies. However, molecular typing provide better discrimination. The various molecular techniques that can be used of typing includes RFLP, rRNA probe technology (ribotyping), PCR amplification restriction endonuclease analysis of chromosomal dhps (dihydropteroate synthase), pil A, pil B and porA genes of $N$. meningitidis, repetitive sequence-based PCR and PFGE. ${ }^{75,76}$ Recently, rapid diagnosis using mass spectrometry and multilocus sequence typing (MLST) using primers designed to target conserved regions of bacterial ribosomal DNA genes (16S and 23S) and genes encoding housekeeping proteins common to all bacteria has been used successfully to identify multiple respiratory microorganisms simultaneously in a quantitative fashion. This allows for broad microbial population analysis and strain tracking of an ongoing, geographically dispersed epidemic on a large scale. ${ }^{77}$ Moreover, bacterial protein microarrays have been prepared for identification of new potential diagnostic markers for $N$. meningitidis infections.

\section{Antimicrobial susceptibility}

Since their introduction in 1937, sulfonamides decreased mortality to $10 \% .^{78}$ In the 1950 s and 1960 s, sulfonamide resistance necessitated a switch to penicillin or chloramphenicol. Since the 1980 s, decreased penicillin susceptibility (MIC, $>0.25 \mathrm{mg} / \mathrm{L}$ ) has been reported in several countries (Spain, Greece, Switzerland, Romania, France, Belgium, United Kingdom, Malawi, South Africa, Canada and the United States). ${ }^{33}$ Most of the relatively resistant meningococci have belonged to either serogroup B or C. Decreased sensitivity to penicillin is caused by a reduced affinity to penicillin binding protein type 2 (PBP2) and PBP3 ${ }^{76,78}$ The altered PBP2 found in $N$. meningitidids strains may have arosen from recombination processes that resulted in replacement of sequences in the native meningococcal pen $\mathrm{A}$ gene with corresponding genetic sequences from commensal Neisseria species. Although, the clinical significance of diminished penicillin susceptibility in $N$. meningitidis is unclear at present both treatment failures and higher rates of complications have been observed. Broad-spectrum cephalosporins, such as cefotaxime, are active against both penicillin susceptible and moderately susceptible $N$. meningitidis strains, but MICs of some agents like cefuroxime, imipenem may be significantly higher than those for susceptible strains.$^{76}$ Penicillin resistance due to plasmidmediated beta-lactamase production has been encountered since 1983 in Canada, South Africa and Spain. ${ }^{79}$ For patients infected with penicillin-resistant strains, broad-spectrum cephalosporins (e.g, ceftriaxone) are recommended.

Isolates with high-level resistance to chloramphenicol have been reported in 1998 in Vietnam and France, but the clinical significance of such resistance needs further evaluation and chloramphenicol remains one of first-line drug for the treatment of cases during epidemics in developing countries. ${ }^{20,80}$ Rifampicin resistance has also, emerged, even during the administration of rifampicin prophylaxis and is due to alterations in cell membrane permeability or to mutations in rpoB gene encoding beta-subunit of the meningococcal 
RNA polymerase. $N$. meningitidis strains with decreased susceptibility to ciprofloxacin have been reported from Australia. ${ }^{81}$ Some strains resistant to tetracycline due to acquired tet $\mathrm{M}$ resistant determinant have also been found. ${ }^{82}$

In India, there has been a paucity of studies on antimicrobial sensitivity of $N$. meningitidis. On searching MEDLINE and INDMED database, only two studies were found to have reported sulphadiazine resistance during meningitis outbreak in Delhi in September 1985- March 1986. ${ }^{38,83}$ Another study from Punjab (Ludhiana) has studied 170 cases of meningococcal meningitis. Among these cases 96 were found culture positive. The study reported all their isolates to be sensitive to most of the common antibiotics including penicillin, chloramphenicol, ampicillin and sulphadiazine. ${ }^{84}$ Isolates obtained from the recent episode (early 2005) of spurt of cases in and around Delhi were subjected to drug susceptibility testing by MIC method (Etest) using break points recently recommended by NCCLS/ CLSI. Most of the isolates were susceptible to commonly used drugs. All the isolates were sensitive to penicillin, ampicillin, rifampicin and ceftriaoxone. As regards to ciprofloxacin, about two third of the isolates tested were found to be 'nonsusceptible' (MIC $\geq 0.03 \mu \mathrm{g} / \mathrm{mL}-0.190 \mu \mathrm{g} / \mathrm{mL}$ ). All the isolates were found resistant to cotrimoxazole (MIC> $16 \mu \mathrm{g} / \mathrm{mL}$ ).

\section{Management}

Meningococcal disease is potentially fatal and should always be viewed as a medical emergency. Admission to a hospital or health center is necessary. Isolation of the patient is not necessary. Management of meningococcal disease requires (i) early recognition of the disease, (ii) prompt initial parenteral antibiotic therapy and (iii) close monitoring with frequent repeated prognostic evaluations. Because of the risks of severe illness and death, however, effective antibiotics should be promptly administered in patients suspected of having meningococcal disease.

Since the clinical presentation of meningitis due to $N$. meningitidis is similar to that of other bacteria (e.g, S. pneumoniae), empirical therapy should be directed at the most likely pathogen on the basis of epidemiologic information. Because of the high prevalence of penicillin-resistant $S$. pneumoniae, empirical management of meningitis in children who are one month of age or older should include vancomycin plus cefotaxime or ceftriaxone. ${ }^{46}$ For children who are less than one month old, the clinician should consider adding vancomycin to the usual antibiotic combination of a broadspectrum cephalosporin and ampicillin. ${ }^{46}$ If $N$. meningitidis is confirmed as the cause of illness, penicillin alone should be given.

During an epidemic situation treatment of large number of patients with multiple injections of crystalline penicillin or even ceftriaxone may be impractical. A single intramuscular dose of an oily suspension of chloramphenicol has been shown to be as effective as a five-day course of crystalline penicillin in the treatment of meningococcal meningitis. ${ }^{85}$ The primary goal of therapy in meningococcal meningitis is to achieve a rapid bactericidal effect in the CSF. Meningococcal meningitis responds to appropriate antibiotics and cerebral abscesses have never been observed. ${ }^{46}$

\section{Prevention and Control}

\section{Chemoprophylaxis}

The primary means for prevention of sporadic meningococcal disease is antimicrobial Chemoprophylaxis of close contacts of infected persons. Mass chemoprophylactic programs are not recommended to control large outbreaks of disease. Disease can be prevented by the eradication of the carrier status in subjects likely to harbor virulent meningococci, e.g, housemates of an index patient. Thus, effective control of emergence of secondary cases is attributed to effective chemoprophylaxis in household members, contacts at day care centers and anyone else directly exposed to an infected patient's oral secretions, e.g, through kissing or mouth-to-mouth resuscitation. ${ }^{22}$ Chemoprophylaxis should be administered to close contacts as soon as possible (ideally within 24 hours after identification of the index patient). Given more than 14 days after the onset of disease, chemoprophylaxis has probably limited or no benefit. ${ }^{86}$

Rifampin, ciprofloxacin, ofloxacin, minocycline, cefixime, sulfadiazine and ceftriaxone are all $90-95 \%$ effective in reducing nasopharyngeal carriage of $N$. meningitidis and are acceptable alternatives for chemoprophylaxis..$^{33,46,53}$

\section{Meningococcal Vaccines}

Invasive disease occurs only in patients devoid of specific bactericidal or opsonizing antibodies and therefore, can be prevented by inducing these antibodies by vaccination. The first vaccine for the prevention of meningococcal disease was developed in 1912. ${ }^{43}$ Scherp and Rake (1935) identified capsular material from a meningococcus as a polysaccharide. ${ }^{43}$ However, real work on meningococcal vaccines started only after emergence of resistance to sulphonamides and penicillin. In the 1960s, polysaccharide vaccines based on group A and $\mathrm{C}$ capsule were developed. ${ }^{46}$ Of the five common serotypes responsible for $>90 \%$ of meningococcal disease, vaccines are available for group A, C, Y and W-135. At present two types of meningococcal vaccines are licensed; meningococcal polysaccharide vaccines (bivalent and quadrivalent) and meningococcal conjugated polysaccharide vaccine.

\section{Meningococcal Polysaccharide Vaccine}

The quadrivalent polysaccharide vaccine that provides protection against serogroups $\mathrm{A}, \mathrm{C}, \mathrm{Y}$ and $\mathrm{W}-135$ and the bivalent polysaccharide vaccines ( $\mathrm{A}$ and $\mathrm{C}$ ) are available worldwide. The efficacy of polysaccharide serogroup A vaccine for preventing serogroup A meningococcal meningitis 
has also been evaluated in several studies reviewed by Patel and Lee. ${ }^{87}$

Primary vaccination for both adults and children older than two years is carried out by administering single $0.5-\mathrm{mL}$ dose, subcutaneously. The vaccine may be recommended for children three months to two years of age under special circumstances. These children should get two doses, three months apart. Each dose consists of $50 \mu \mathrm{g}$ of the four purified bacterial capsular polysaccharides. The vaccine can be administered at the same time as other vaccines but should be given at a different anatomic site. The antibody responses to each of the four polysaccharides in the quadrivalent vaccine are serogroup-specific and independent. Protective levels of antibody are usually achieved within 7-10 days of vaccination.

The immunogenicity and clinical efficacy of the serogroups $\mathrm{A}$ and $\mathrm{C}$ meningococcal vaccines have been well established. The serogroup A polysaccharide induces antibody in some children as young as three months of age, although a response comparable with that occurring in adults is not achieved until age 4-5 years. The serogroup $\mathrm{C}$ component is poorly immunogenic in children less than 2 years. ${ }^{88}$ These unconjugated polysaccharide vaccines confer protection in complement deficient persons also. ${ }^{53}$ The serogroup A and C vaccines have good immunogenicity, with clinical efficacy rates of 85 percent or higher among children five years of age or older and adults. ${ }^{53,89}$ Serogroup $Y$ and W-135 polysaccharides are safe and immunogenic in older children and adults; although clinical protection has not been documented, vaccination with these polysaccharides induces bactericidal antibody ${ }^{46}$ Vaccination has been highly effective in the control of community outbreaks and epidemics in military centers. ${ }^{53,89}$ Similarly, these polysaccharide vaccines are able to control large epidemics in African countries in the meningitis belt, provided that surveillance is adequate and the vaccination is started before the epidemic threshold is passed. ${ }^{90}$ Vaccination does not reduce the transfer of bacteria to nonvaccinated persons and carrier status is unaffected..$^{91}$

In infants and young children aged $<5$ years, measurable levels of antibodies against serogroup $A$ and $C$ polysaccharides, as well as clinical efficacy, decrease substantially during the first three years after a single dose of the vaccine has been administered. Antibody levels also decrease in healthy adults, but antibodies are still detectable up to 10 years after immunization..$^{46,53,88}$

Although a reduction in clinical efficacy has not been demonstrated in persons who have received multiple doses of vaccine, recent serologic studies suggest that multiple doses of serogroup $\mathrm{A}$ and $\mathrm{C}$ polysaccharides may cause immunologic tolerance of the polysaccharides. ${ }^{46,53}$

Extensive experience with this vaccine has demonstrated its safety; adverse effects are generally mild, the most frequent reaction is pain and redness at the site of injection, lasting for 1-2 days. ${ }^{53,92}$ Estimates of the incidence of such local reactions have varied, ranging from 4 to $56 \% .{ }^{92,93}$ Transient fever occurred in up to $5 \%$ of vaccinees in some studies and occurs more commonly in infants. ${ }^{53}$ Severe reactions to polysaccharide meningococcal vaccine are uncommon. ${ }^{53}$

The value of this kind of vaccines is limited because these "thymus-independent" vaccines do not induce immunological memory and the response in children younger than two years is poor. ${ }^{94}$

The major drawback of the presently available vaccines is the absence of activity against group B meningococci, which is common serotype in some Western European countries. Since group B polysaccharide is a 200 -residue ( $\alpha 2-8)$ homopolymer of $\mathrm{N}$-acetylneuraminic acid (poly2-8NeuNAc) that mimics the human neuronal cell adhesion molecule, the use of group B capsule in a vaccine risks the induction of autoimmunity. ${ }^{95}$ In any case however, since the antibody response to the group B capsule is limited after natural infections, group B capsular polysaccharide is a poor candidate for vaccine development. ${ }^{96}$

\section{Meningococcal conjugated polysaccharide vaccine}

In the United Kingdom, serogroup $C$ conjugate vaccines were added to the routine schedule of childhood immunizations in late $1999 .{ }^{97}$ A quadrivalent A, C, Y and W135 conjugate vaccine has been licensed in United States in January 2005 . It is speculated that $~ 70 \%$ of the disease in individuals older than 10 years would be vaccine preventable. This vaccine contains $4 \mu \mathrm{g}$ each of $\mathrm{A}, \mathrm{C}, \mathrm{Y}$ and $\mathrm{W}-135$ polysaccharide conjugated to $48 \mu \mathrm{g}$ of diphtheria toxoid (Menactra; Aventis Pasteur).

These meningococcal conjugate vaccines induce a T-celldependent response, resulting in an improved immune response in infants, priming immunologic memory and leading to a booster response to subsequent doses. ${ }^{46}$ These vaccines provide long-lasting immunity even when given as a series in infancy and thus induce herd immunity through protection from nasopharyngeal carriage. For $N$. meningitidis, oligosaccharides from purified capsular polysaccharide are covalently conjugated to inactivated bacterial carrier proteins (tetanus toxoid or diphtheria $\mathrm{CRM}_{197}$ ) yielding a $\mathrm{T}$ cell dependent antigen. ${ }^{98}$ These vaccines have been found safe, immunogenic and have acceptable reactogenicity in all ages. Nasopharnygeal carriage rates may also be decreased by use of the conjugate vaccine, reducing bacterial transmission. ${ }^{98}$

The conjugated polysaccharide vaccine is contraindicated in patients with a known hypersensitivity to any component of the vaccine, including diphtheria toxoid and in patients with a history of a severe reaction to any other vaccine containing similar components. 


\section{Recommendations for use of meningococcal vaccine}

Routine childhood vaccination with the meningococcal polysaccharide vaccine is not recommended because of its relative ineffectiveness in young children aged $<2$ years, who have the highest risk of sporadic disease and a relatively short duration of protection. ${ }^{86}$ Furthermore, even large scale coverage with current vaccines does not provide sufficient "herd immunity". Consequently, the current WHO recommendation for outbreak control is to mass vaccinate every district that is in an epidemic phase, as well as those contiguous districts that are in alert phase. It is estimated that a mass immunization campaign, promptly implemented, can avoid $70 \%$ of cases. (http://www.who.int/mediacentre/ factsheets/fs141/en/index.html).

Routine vaccination with the vaccine is recommended for certain high-risk groups, including persons who have terminal complement component deficiencies and those who have anatomic or functional asplenia. Laboratory personnel and healthcare workers who are exposed routinely to Neisseria meningitidis in solutions that may be aerosolized should also be considered for vaccination. ${ }^{86}$

Epidemics in the meningitis belt usually occur during the dry season (i.e, from December to June); thus, vaccination with the vaccine may benefit travelers to the part of subSaharan Africa known as the "meningitis belt". ${ }^{53}$ Vaccination with a single dose of polysaccharide vaccine is recommended for travelers above 18 months of age going to an area experiencing an epidemic of meningococcal disease or to areas with a high rate of endemic meningococcal disease. Since the epidemic of meningococcal disease that occurred in 1987 during the Hajj in Mecca, proof of vaccination against meningococcus has been required for the pilgrims to the Hajj or Umra, at their entry in Saudi Arabia. More information concerning geographic areas for which vaccination is recommended can be obtained from internet (http:// www.cdc.gov/travel/).

Revaccination may be indicated for persons at high risk for infection (e.g, persons residing in areas in which disease is epidemic), particularly for children who were first vaccinated when they were $<4$ years of age; such children should be considered for revaccination after 2-3 years if they remain at high risk. ${ }^{86}$

\section{Newer approaches to meningococcal vaccines}

Unlike serogroup A and C polysaccharides, the serogroup B polysaccharide has a capsule [( $\alpha 2-8)$-linked polysialic acid] that is identical in structure to polysialic acid in foetal neural tissue and is poorly immunogenic in humans. ${ }^{96}$ Therefore, conjugated chemically modified group B capsule where the $N$-acetyl group has been replaced by the $N$-propionyl group is being tried. ${ }^{99}$ Strategies for developing vaccines against serogroup B disease have therefore focused primarily on noncapsular antigens (e.g, outer-membrane proteins). ${ }^{100}$
To improve the immunogenicity of the serogroup B polysaccharide, researchers have covalently linked it to carrier proteins and adsorbed it to aluminum; this vaccine has induced a serogroup-specific response in animals. Use of serogroup B polysaccharide vaccines in humans has been limited because of the theoretical risk that these vaccines will overcome immune tolerance and induce autoimmunity. Another approach to serogroup $\mathrm{A}$ and $\mathrm{C}$ polysaccharides has been the use of peptides that mimic the capsular polysaccharide in complex with or conjugated to potent carrier-protein molecules in order to elicit a T-cell-dependent response. ${ }^{101}$ Among other approaches, live vaccine with $N$. lactamica for serogroup B and C, subunit vaccines based on capsular polysaccharide, outer membrane vesicle (OMV) using outer membrane protein including $\mathrm{NspA}$, a conserved protein to serotypes A, B, and C are also under research. ${ }^{102}$

\section{References}

1. Vieusseux M. Mémoire sur la maladie qui a regné a Genêve au printemps de 1805. J Med Chir Pharmacol 1805;11:163.

2. Weichselbaum A. Ueber die Aetiologie der akuten Meningitis cerebrospinalis. Fortschr Med 1887;5:573-83.

3. Marchiafava E, Celli A. Spra i micrococchi della meningite cerebrospinale epidemica. Gazz degli Ospedali 1884;5:59.

4. Flexner S. The results of serum treatment in thirteen hundred cases of epidemic meningitis. J Exp Med 1913;17:553-76.

5. Jochmann G. Versuche zur Serodiagnostik un Serotherapie der epidemischen Genickstarre. Dtsch Med Wochenschr 1906;1:788-93

6. Rosenstein NE, Perkins BA. Update on Haemophilus influenzae serotype $\mathrm{b}$ and meningococcal vaccines. Pediatr Clin North Am 2000;47:337-52.

7. Kirsch EA, Barton RP, Kitchen L, Giroir BP. Pathophysiology, treatment and outcome of meningococcemia:a review and recent experience. Pediatr Infect Dis J 1996;15:967-79.

8. Caugant DA. Population genetics and molecular epidemiology of Neisseria meningitidis. APMIS 1998;106:505-25.

9. Frasch CE, Zollinger WD, Poolman JT. Serotype antigens of Neisseria meningitidis and a proposed scheme for designation of serotypes. Rev Infect Dis 1985;7:504-10.

10. Scholten RJ, Kuipers B, Valkenburg HA, Dankert J, Zollinger WD, Poolman JT. Lipo-oligosaccharide immunotyping of Neisseria meningitidis by a whole-cell ELISA with monoclonal antibodies. J Med Microbiol. 1994;41:236-43.

11. Mandrell RE, Zollinger WD. Lipopolysaccharide serotyping of Neisseria meningitidis by hemagglutination inhibition. Infect Immun 1977;16:471-5.

12. Stephens DS, Whitney AM, Rothbard J, Schoolnik GK. Pili of Neisseria meningitidis. Analysis of structure and investigation of structural and antigenic relationships to gonococcal pili. $J$ Exp Med 1985;161:1539-53. 
13. Taha MK, Alonso JM, Cafferkey M, Caugant DA, Clarke SC, Diggle MA, et al. Interlaboratory comparison of PCR-based identification and genogrouping of Neisseria meningitidis. J Clin Microbiol 2005;43:144-9.

14. Swartley JS, Marfin AA, Edupuganti S, Liu LJ, Cieslak P, Perkins B, et al. Capsule switching of Neisseria meningitidis. Proc Natl Acad Sci U S A 1997;94:271-6.

15. Stephens DS. Uncloacking the meningococcus:dynamics of carriage and disease. Lancet 1999;353:941-2.

16. Maiden MC, Bygraves JA, Feil E, Morelli G, Russell JE, Urwin $\mathrm{R}$, et al. Multilocus sequence typing: a portable approach to the identification of clones within populations of pathogenic microorganisms. Proc Natl Acad Sci U S A 1998;95:3140-5.

17. Bjorvatn B, Hassan-King M, Greenwood B, Haimanot RT, Fekade D, Sperber G. DNA fingerprinting in the epidemiology of African serogroup A Neisseria meningitidis. Scand J Infect Dis 1992;24:323-32.

18. Achtman M. Global epidemiology of meningococcal disease. In: Meningococcal disease. Cartwright K, Editors. John Wiley \& Sons Ltd: Chichester, United Kingdom; 1995. p. 159-75.

19. Schwartz B, Moore PS, Broome CV. Global epidemiology of meningococcal disease. Clin Microbiol Rev 1989;2:S118-24.

20. World Health Organization Working Group. Control of epidemic meningococcal diseases: WHO practical guidelines. Lyon, France: Edition Foundation Marcel Merieux; 1995.

21. Rosenstein NE, Perkins BA, Stephens DS, Lefkowitz L, Cartter ML, Danila R, et al. The changing epidemiology of meningococcal disease in the United States, 1992-1996. J Infect Dis 1999;180:1894-901.

22. Connolly M, Noah N. Is group $\mathrm{C}$ meningococcal disease increasing in Europe? A report of surveillance of meningococcal infection in Europe 1993-6. Epidemiol Infect 1999;122:41-9.

23. Band JD, Chamberland ME, Platt T, Weaver RE, Thornsberry C, Fraser DW. Trends in meningococcal disease in the United States, 1975-1980. J Infect Dis 1983;148:754-8.

24. Popovic T, Sacchi CT, Reeves MW, Whitney AM, Mayer LW, Noble CA, et al. Neisseria meningitidis serogroup W135 isolates associated with the ET-37 complex. Emerg Infect Dis 2000;6:428-9.

25. Taha MK, Achtman M, Alonso JM, Greenwood B, Ramsay M, Fox A, et al. Serogroup W135 meningococcal disease in Hajj pilgrims. Lancet 2000;356:2159.

26. Riou JY, Djibo S, Sangare L, Lombart JP, Fagot P, Chippaux $\mathrm{JP}$, et al. A predictable comeback:the second pandemic of infections caused by Neisseria meningitidis serogroup A subgroup III in Africa, 1995. Bull World Health Organ 1996;74:181-7.

27. Vogel G. Infectious disease. Shortage of meningitis vaccine forces triage in Burkina Faso. Science 2003;299:1499-501.

28. Fischer M, Perkins BA. Neisseria meningitidis serogroup
B:emergence of the ET-5 complex. Semin Pediatr Infect Dis 1997;8:50-6.

29. Kertesz DA, Coulthart MB, Ryan JA, Johnson WM, Ashton FE. Serogroup B, electrophoretic type 15 Neisseria meningitidis in Canada. J Infect Dis 1998;177:1754-7.

30. Scholten RJ, Poolman JT, Valkenburg HA, Bijlmer HA, Dankert J, Caugant DA. Phenotypic and genotypic changes in a new clone complex of Neisseria meningitidis causing disease in The Netherlands, 1958-1990. J Infect Dis 1994;169:673-6.

31. Greenwood BM, Bradley AK, Wall RA. Meningococcal disease and season in sub-Saharan Africa. Lancet 1985;2:829-30.

32. Response to epidemic meningitis in Africa, 1997. Wkly Epidemiol Rec 1997;42:313-8.

33. van Deuren M, Brandtzaeg P, van der Meer JW. Update on meningococcal disease with emphasis on pathogenesis and clinical management. Clin Microbiol Rev 2000;13:144-66.

34. http://w3.whosea.org/EN/Section10/Section1973_9755.htm (WHO website) Accessed June17, 2005.

35. CD alert. Monthly Newsletter of National Institute of Communicable Diseases. Directorate General of Health Services: Government of India; 2005;9:1-8.

36. Basu RN, Prasad R, Ichhpujani RL. Meningococcal meningitis in Delhi and Other areas. Commun Dis Bull 1985;2:1

37. Suri M, Kabra M, Singh S, Rattan A, Verma IC. Group B meningococcal meningitis in India. Scand J Infect Dis 1994;26:771-3.

38. Ayyagari A, Dubey ML, Bhandari SK. Sulphadiazine resistant strains of Neisseria meningitidis during an outbreak of meningococcal meningitis. Indian J Med Res 1987;85:249-52.

39. Ichhpujani RL, Mohan R, Grover SS, Joshi PR, Kumari S. Nasopharyngeal carriage of Neisseria meningitidis in general population and meningococcal disease. J Commun Dis 1990;22:264-8.

40. Paul VK, Bhujwala RA, Ghai OP, Shriniwas, Ahuja GK, Verma IC, et al. Nasopharyngeal carriers among contact of patients of Neisseria meningitidis infection in Delhi. Indian J Med Res 1987;86:429-32

41. Bhavsar BS, Saxena DM, Kantharia SL, Somasunderam C, Mehta NR. Meningococcal meningitis in an industrial area adjoining Surat City-some clinico-epidemiological aspects. $J$ Commun Dis 1989;21:96-106.

42. Annapurna ME, Bhave GG, Mathur M. An outbreak of meningitis caused by Neisseria meningitidis Group A. J Commun Dis 1989;21:24-6.

43. Cartwright KAV. Bacterial meningitis, Chapter 17. In: Topley and Wilson's Microbiology and Microbial Infections, $9^{\text {th }}$ edn. Collier L, Balows A, Sussman M, editors. Oxford University Press: New York; 1996. p. 299-318.

44. Goldschneider I, Gotschlich EC, Artenstein MS. Human 
immunity to the meningococcus. I. The role of humoral antibodies. J Exp Med 1969;129:1307-26.

45. Moore PS, Reeves MW, Schwartz B, Gellin BG, Broome CV. Intercontinental spread of an epidemic group A Neisseria meningitidis strain. Lancet 1989;2:260-3.

46. Rosenstein NE, Perkins BA, Stephens DS, Popovic T, Hughes JM. Meningococcal disease. N Engl J Med 2001;344:1378-88.

47. Aycock WL, Mueller JH. Meningococcus carrier rates and meningitis incidence. Bacteriol Rev 1950;14:115-60.

48. Goldschneider I, Gotschlich EC, Artenstein MS. Human immunity to the meningococcus. II. Development of natural immunity. J Exp Med 1969;129:1327-48.

49. Gold R. Bacterial meningitis-1982. Am J Med 1983;75:98-101.

50. Grados O, Ewing WH. Antigenic relationship between Escherichia coli and Neisseria meningitidis. J Infect Dis 1970;122:100-3.

51. Vann WF, Liu TY, Robbins JB. Bacillus pumilus polysaccharide cross-reactive with meningococcal group A polysaccharide. Infect Immun 1976;13:1654-62.

52. Figueroa JE, Densen P. Infectious diseases associated with complement deficiencies. Clin Microbiol Rev 1991;4:359-95.

53. Recommendations of the Advisory Committee on Immunization Practices (ACIP). Prevention and Control of Meningococcal Disease. MMWR 2000;49:1-10.

54. Stephens DS, Hoffman LH, McGee ZA. Interaction of Neisseria meningitidis with human nasopharyngeal mucosa: attachment and entry into columnar epithelial cells. J Infect Dis 1983;148:369-76.

55. Schildkamp RL, Lodder MC, Bijlmer HA, Dankert J, Scholten RJ. Clinical manifestations and course of meningococcal disease in 562 patients. Scand J Infect Dis 1996;28:47-51.

56. Ploysangam T, Sheth AP. Chronic meningococcemia in childhood: case report and review of the literature. Pediatr Dermatol 1996;13:483-7.

57. Wells M, Gibbons RB. Primary meningococcal arthritis:case report and review of the literature. Mil Med 1997;162:769-72.

58. Blaser MJ, Reingold AL, Alsever RN, Hightower A. Primary meningococcal pericarditis: a disease of adults associated with serogroup C Neisseria meningitidis. Rev Infect Dis 1984;6:62532 .

59. Ødegaard A. Unusual manifestations of meningococcal infection. A review. NIPH Ann. 1983;6:59-63.

60. Stephens DS, Hajjeh RA, Baughman WS, Harvey RC, Wenger JD, Farley MM. Sporadic meningococcal disease in adults: results of a 5-year population-based study. Ann Intern Med 1995;123:937-40.

61. Caugant DA, Høiby EA, Frøholm LO, Brandtzaeg P. Polymerase chain reaction for case ascertainment of meningococcal meningitis:application to the cerebrospinal fluids collected in the course of the Norwegian meningococcal serogroup B protection trial. Scand J Infect Dis 1996;28:14953.

62. van Deuren M, van Dijke BJ, Koopman RJ, Horrevorts AM, Meis JF, Santman FW, et al. Rapid diagnosis of acute meningococcal infections by needle aspiration or biopsy of skin lesions. BMJ 1993;306:1229-32.

63. Laboratory Methods for the Diagnosis of Meningitis Caused by Neisseria meningitidis, Streptococcus pneumoniae and Haemophilus influenzae. Centers for Disease Control and Prevention 1998.

64. Control of epidemic meningococcal disease. WHO practical guidelines. $2^{\text {nd }}$ ed. World Health Organisation.WHO/EMC/BAC/ 98.3. World Health Organization: Geneva; 1998. p. 1-84.

65. Dunbar SA, Eason RA, Musher DM, Clarridge JE. Microscopic examination and broth culture of cerebrospinal fluid in diagnosis of meningitis. J Clin Microbiol 1998;36:1617-20.

66. Zollinger WD, Boslego J. Immunologic methods for diagnosis of infections by gram-negative cocci. In: Manual of clinical laboratory immunology, $5^{\text {th }}$ edn. Rose NR, Conway de Macario E, Folds JD, Lane HC, Nakamura RM, editors. ASM Press: Washington DC; 1997. p. 473-83.

67. Clinical and Laboratory Standard Institute. Performance standards for antimicrobial susceptibility testing M100-S15. Clinical and Laboratory Standard Institute: Wayne, Pennsylvania; 2005.

68. Hughes JH, Biedenbach DJ, Erwin ME, Jones RN. E test as susceptibility test and epidemiologic tool for evaluation of Neisseria meningitidis isolates. J Clin Microbiol 1993;31:32559.

69. Richardson DC, Louie L, Louie M, Simor AE. Evaluation of a rapid PCR assay for diagnosis of meningococcal meningitis. $J$ Clin Microbiol 2003;41:3851-3.

70. Jordens JZ, Heckels JE. A novel porA-based real-time PCR for detection of meningococcal carriage. J Med Microbiol 2005;54:463-6.

71. Fernandez-Rodriguez A, Vazquez JA, Suarez-Mier MP, Aguilera B, Ballesteros S, De la Fuente L, et al. Latex agglutination for bacterial antigens and meningococcus PCR: two useful tools in legal sudden deaths. Forensic Sci Int 2005;147:13-20.

72. de Filippis I, do Nascimento CR, Clementino MB, Sereno AB, Rebelo C, Souza NN, et al. Rapid detection of Neisseria meningitidis in cerebrospinal fluid by one-step polymerase chain reaction of the nspA gene. Diagn Microbiol Infect Dis 2005;51:85-90.

73. Mothershed EA, Sacchi CT, Whitney AM, Barnett GA, Ajello GW, Schmink S, et al. Use of real-time PCR to resolve slide agglutination discrepancies in serogroup identification of Neisseria meningitidis. J Clin Microbiol 2004;42:320-8.

74. Tzanakaki G, Tsopanomichalou M, Kesanopoulos K, Matzourani R, Sioumala M, Tabaki A, et al. Simultaneous single-tube PCR 
assay for the detection of Neisseria meningitidis, Haemophilus influenzae type b and Streptococcus pneumoniae. Clin Microbiol Infect 2005;11:386-90.

75. Healy M, Huong J, Bittner T, Lising M, Frye S, Raza S, et al. Microbial DNA typing by automated repetitive-sequence-based PCR. J Clin Microbiol 2005;43:199-207.

76. Janda WM, Knapp JS. Neisseria and Moraxella catarrhalis, Chapter 38. In: Manual of clinical microbiology, $8^{\text {th }}$ edn Murry PR, Barron EJ, Pfaller MA, Jorgensen JH, Yolken RH, editors. ASM Press: Washington DC; 2003. p. 585-608.

77. Ecker DJ, Sampath R, Blyn LB, Eshoo MW, Ivy C, Ecker JA, et al. Rapid identification and strain-typing of respiratory pathogens for epidemic surveillance. Proc Natl Acad Sci U S A 2005; 102:8012-7.

78. Schwentker FF, Gelman S, Long PH. The treatment of meningococcal meningitis with sulfanilamide. Preliminary report. JAMA 1937;108:1407-8.

79. Dillon JR, Pauze M, Yeung KH. Spread of penicillinaseproducing and transfer plasmids from the gonococcus to Neisseria meningitidis. Lancet 1983;1:779-81.

80. Galimand M, Gerbaud G, Guibourdenche M, Riou JY, Courvalin P. High-level chloramphenicol resistance in Neisseria meningitidis. N Engl J Med 1998;339:868-74.

81. Shultz TR, Tapsall JW, White PA, Newton PJ. An Invasive Isolate of Neisseria meningitidis Showing Decreased Susceptibility to Quinolones. Antimicrob. Agents Chemother 2000;44:1116.

82. Winterscheid KK, Whittington WL, Roberts MC, Schwebke JR, Holmes KK. Decreased susceptibility to penicillin G and Tet M plasmids in genital and anorectal isolates of Neisseria meningitidis. Antimicrob Agents Chemother 1994;38:1661-3.

83. Sarkar R, Sharma S, Natarajan R, Agarwal DS. Sulphadiazine resistant group 'A' meningococci isolated during the meningitis outbreak in Delhi (1985). Indian J Med Res 1987;85:612-6.

84. Kumar R, Khurana S, Gupta BK. Meningococcal meningitis in Ludhiana. Indian J Pathol Microbiol. 1992;35:340-4.

85. Pecoul B, Varaine F, Keita M, Soga G, Djibo A, Soula G, et al. Long-acting chloramphenicol versus intravenous ampicillin for treatment of bacterial meningitis. Lancet 1991;338:862-6.

86. Control and prevention of serogroup $\mathrm{C}$ meningococcal disease: evaluation and management of suspected outbreaks: recommendations of the Advisory Committee on Immunization Practices (ACIP). Morb Mortal Wkly Rep 1997;46:13-21.

87. Patel M, Lee CK. Polysaccharide vaccines for preventing serogroup A meningococcal meningitis. The Cochrane Database of Systematic Reviews 2005, Issue 1. Art. No.:CD001093.pub2. DOI:10.1002/14651858.CD001093.pub2.

88. Gold R, Lepow ML, Goldschneider I, Draper TF, Gotschlich
EC. Kinetics of antibody production to group A and group C meningococcal polysaccharide vaccines administered during the first six years of life: prospects for routine immunization of infants and children. J Infect Dis 1979;140:690-7.

89. Rosenstein N, Levine O, Taylor JP, Evans D, Plikaytis BD, Wenger JD, et al. Efficacy of meningococcal vaccine and barriers to vaccination. JAMA 1998;279:435-9.

90. Veeken H, Ritmeijer K, Hausman B. Priority during a meningitis epidemic: vaccination or treatment? Bull WHO 1998;76:13541.

91. Moore PS, Harrison LH, Telzak EE, Ajello GW, Broome CV. Group A meningococcal carriage in travelers returning from Saudi Arabia. JAMA 1988;260:2686-9.

92. Lepow ML, Beeler J, Randolph M, Samuelson JS, Hankins WA. Reactogenicity and immunogenicity of a quadrivalent combined meningococcal polysaccharide vaccine in children. $J$ Infect Dis 1986;154:1033-6.

93. Scheifele DW, Fjornson G, Boraston S. Local adverse effects of meningococcal vaccine. Can Med Assoc J 1994;150:14-5.

94. Ceesay SJ, Allen SJ, Menon A, Todd JE, Cham K, Carlone GM, et al. Decline in meningococcal antibody levels in African children 5 years after vaccination and the lack of an effect of booster immunization. J Infect Dis 1993;167:1212-6.

95. Finne J, Leinonen M, Makela PH. Antigenic similarities between brain components and bacteria causing meningitis. Implications for vaccine development and pathogenesis. Lancet 1983;2:3557.

96. Griffiss JM, Yamasaki R, Estabrook M, Kim JJ. Meningococcal molecular mimicry and the search for an ideal vaccine. Trans R Soc Trop Med Hyg 1991;85:S32-6.

97. Ramsay ME Andrews N, Kaczmarski EB, Miller E. Efficacy of meningococcal serogroup $\mathrm{C}$ conjugate vaccine in teenagers and toddlers in England. Lancet 2001;357:195-6.

98. Healy CM, Baker CJ. The future of meningococcal vaccines. Pediatr Infect Dis J 2005;24:175-6.

99. Jennings HJ. N-propionylated group B meningococcal polysaccharide glycoconjugate vaccine against group B meningococcal meningitis. Int J Infect Dis 1997;1:158-64.

100. Frasch CE. Vaccines for prevention of meningococcal disease. Clin Microbiol Rev 1989;2:S134-8.

101. Diaz Romero J, Outschoorn IM. Current status of meningococcal group B vaccine candidates: capsular or noncapsular? Clin Microbiol Rev 1994;7:559-75.

102. Haneberg B, Dalseg R, Wedege E, Hoiby EA, Haugen IL, Oftung F, et al. Intranasal administration of a meningococcal outer membrane vesicle vaccine induces persistant local mucosal antibodies and serum antibodies with strong bactericidal activity in humans. Infect Immun 1998;66:1334-41. 